\title{
Utilização das Metas Internacionais de Segurança do Paciente para fortalecimento da Cultura de Segurança
}

21 de março de 2019

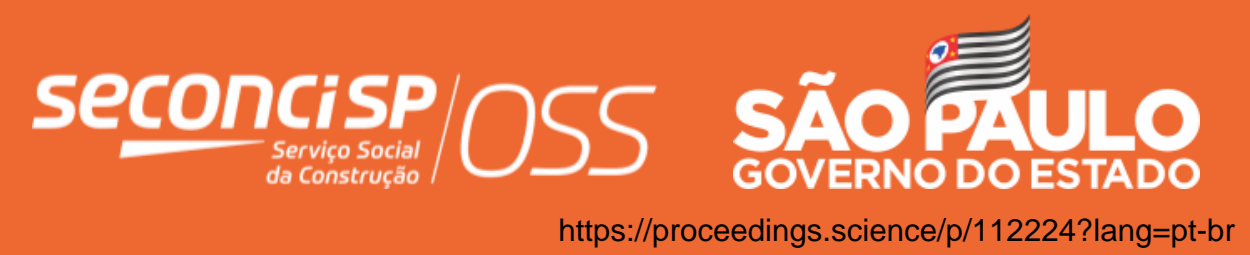




\section{Produção}

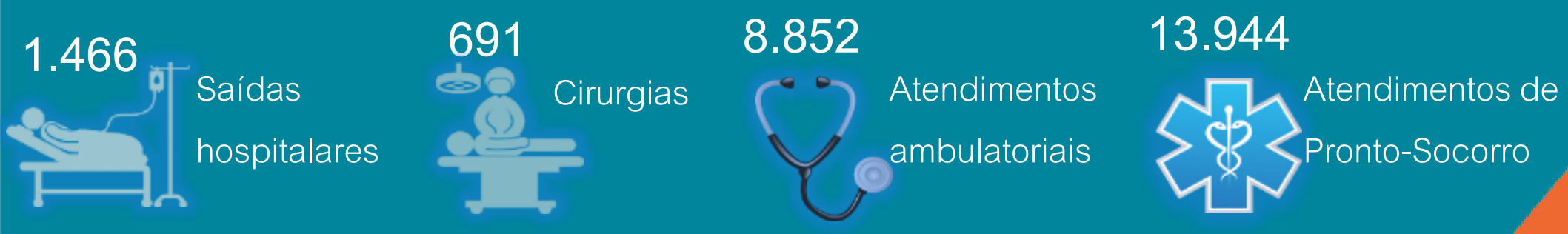

\section{Nossos números}

Média Mensal 2018

Recursos Humanos

\subsection{2}

colaboradores
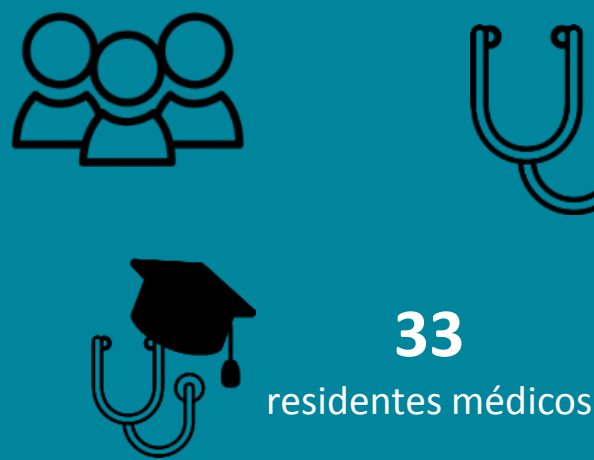

310 médicos

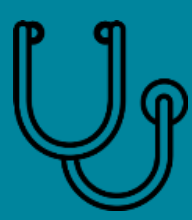

$12.271,77 \mathrm{~m}^{2}$
Estrutura física de área construída

07 salas cirúrgicas
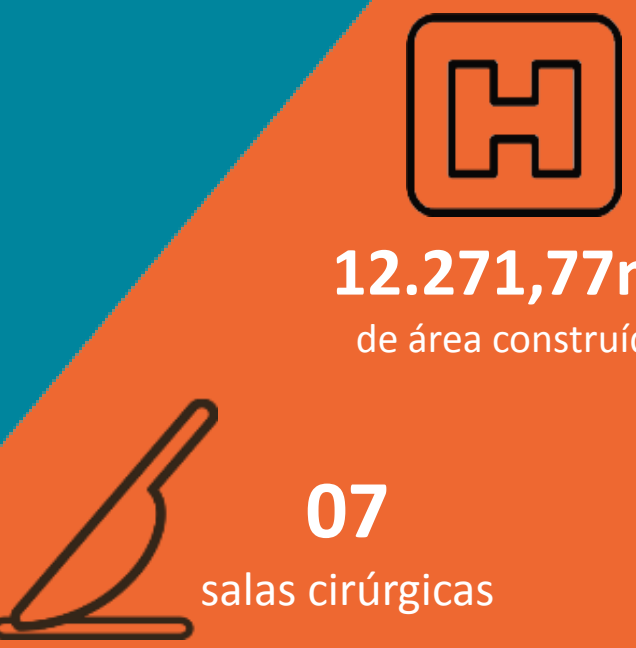

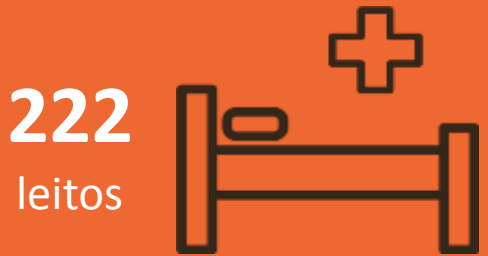

sendo

36

leitos de UTI 


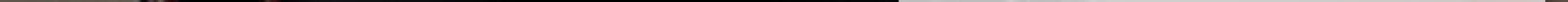




\section{Projeto de}

Intervenção

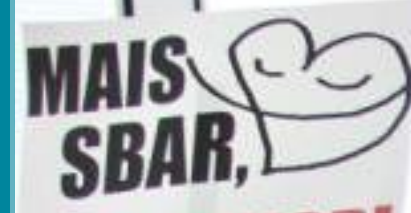

POR FAVORI

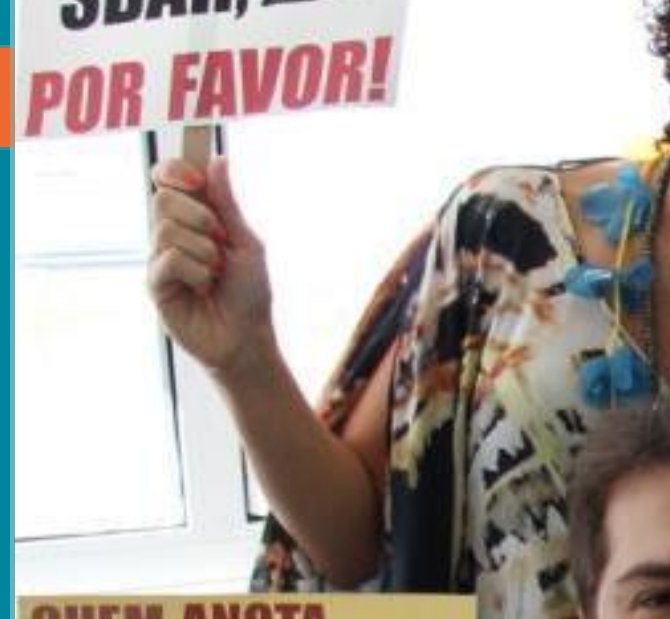

QUEM ANOTA

ELE DE TOLTA

RESULTADO GRITICO?

ESSE GARA

- Revisão de Protocolos

- Elaboração de Políticas, Protocolos e Procedimentos Operacionais Padrão

- Elaboração de instrumentos para o cuidado e para as auditorias 


\section{Projeto de Intervenção}

Meta 1- Identificar corretamente o paciente

- Identificadores

- Situações especiais

- Local

- Cor

- Quando verificar 
Projeto de Intervenção

- Lista de medicamentos

- Forma de rotulagem

GILANCIA P:

Meta 3 - Melhorar a segurança de medicamentos de alta vigilância

- Fluxo de entrega e armazenagem 


\section{Projeto de Intervenção}

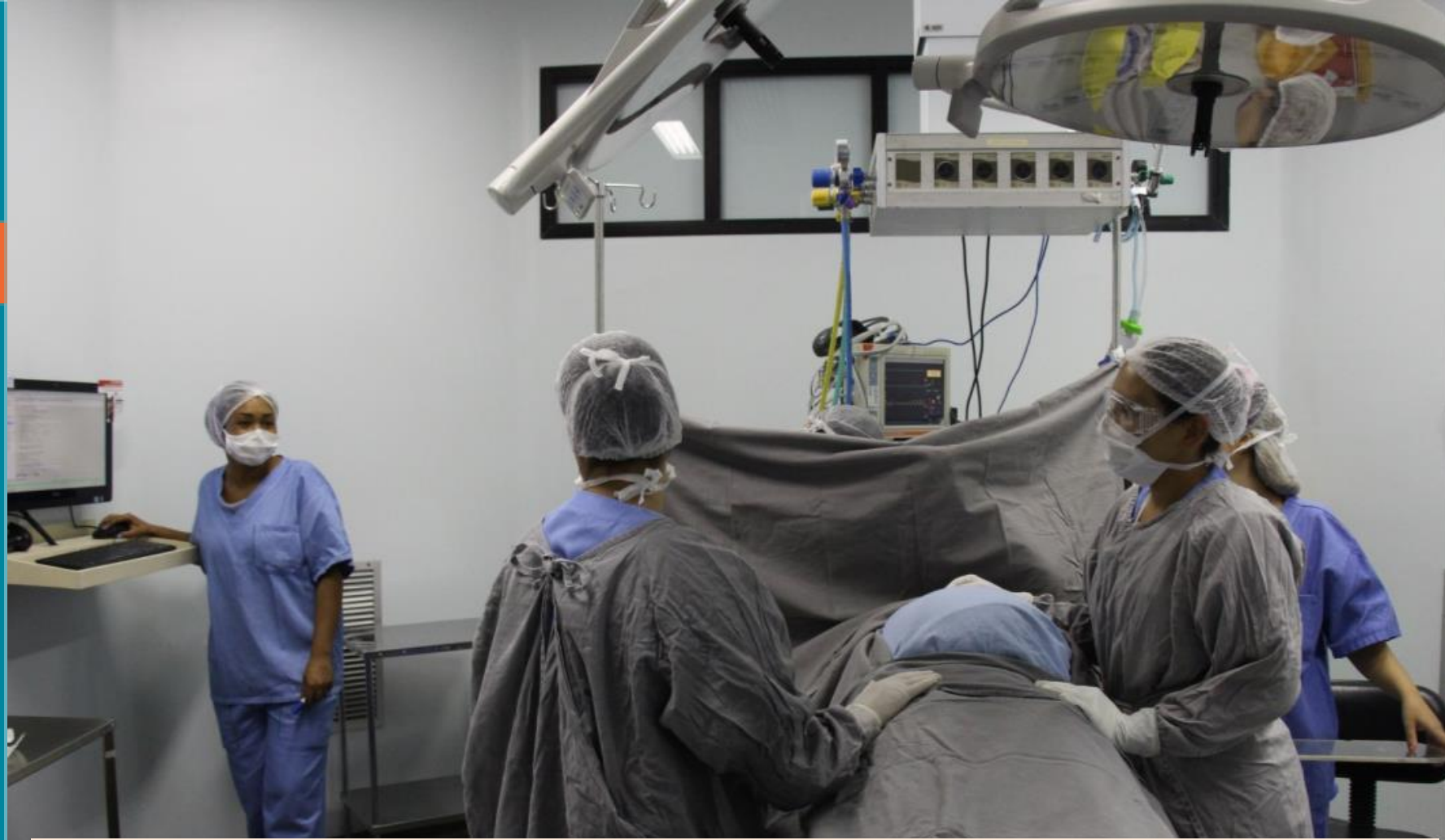

Meta 4-Garantir cirurgia segura

- Padronização de marcação

- Sign in, Time out, Sign out

- Responsabilidades

- Impressos / templates 


\section{Projeto de Intervenção}

Meta 5 - Reduzir o risco de infecções associadas a cuidados de saúde

○ 5 momentos

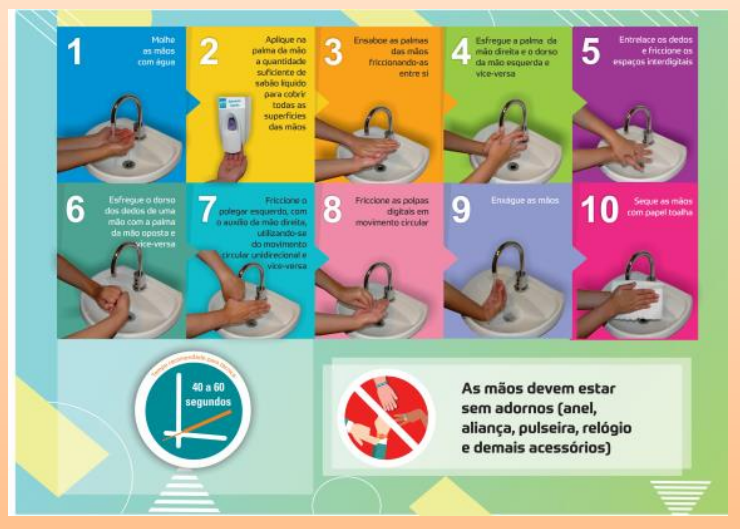




\section{Projeto de Intervenção}

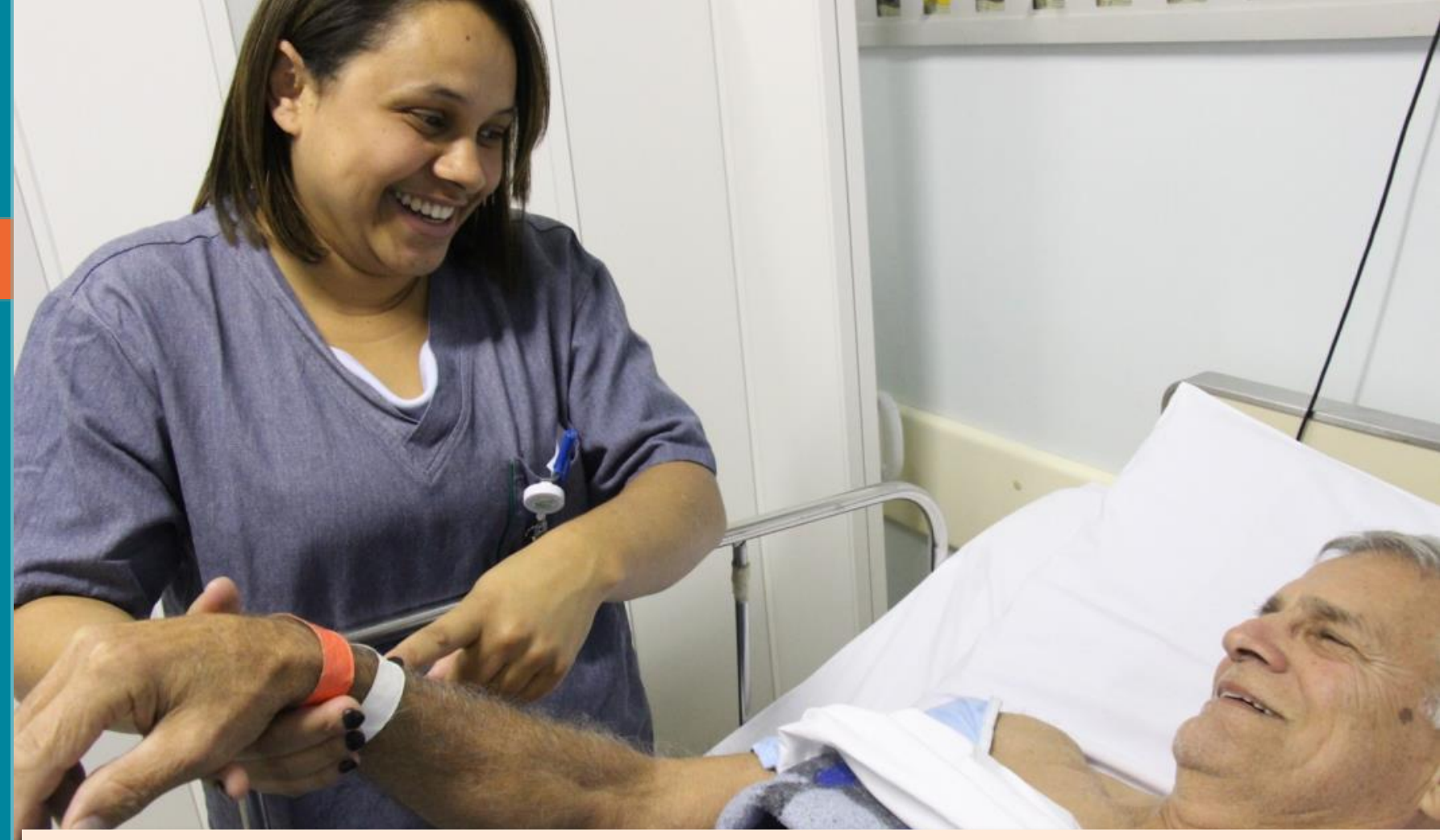

Meta 6 - Reduzir o risco de danos aos pacientes resultantes de queda

- Como, quem e quando

- Escalas: Humpty Dumpty, Jonhs Hopkins e OFRAS

- Medidas de prevenção

- Educação do paciente 


\section{Disseminação}

HE: IU⿴囗十⺝ISS ATITUDES

Meta 1 Meta 2 Meta 3 Meta 4 Meta 5 Meta 6
$\left(\begin{array}{ll}1 \\ 1\end{array}\right] \sqrt{1} 1150$ RESULTADOS

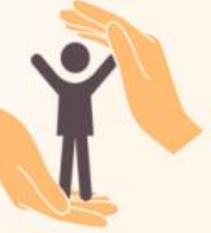

Campanha das Metas Internacionais de Segurança do Paciente

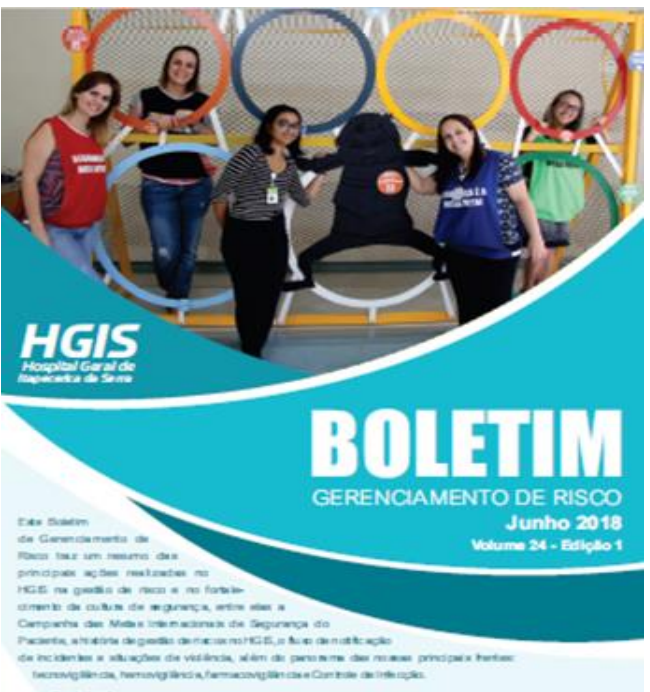

赵

seconcisp/OSS

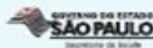

\section{(is) RisCD}

Série Historicica das Incidências dos Eventos na UTI Adulto

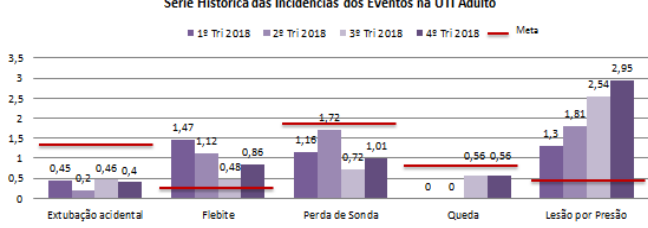
Taxa de adeš̃o is Metas Internacionais de Segras

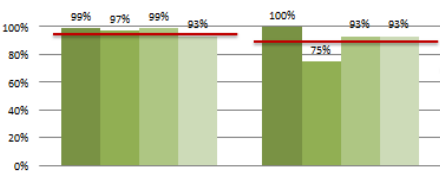

Meta 1 Meta 2

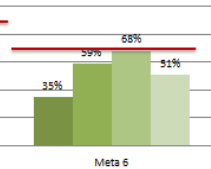

meta 5

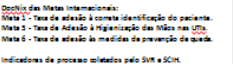

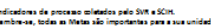



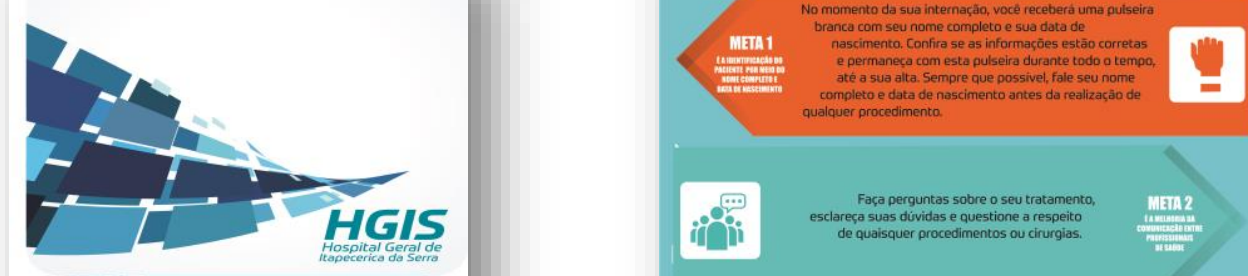

yor

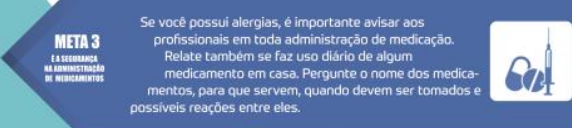
corretamente

METa 1

ando ratar?
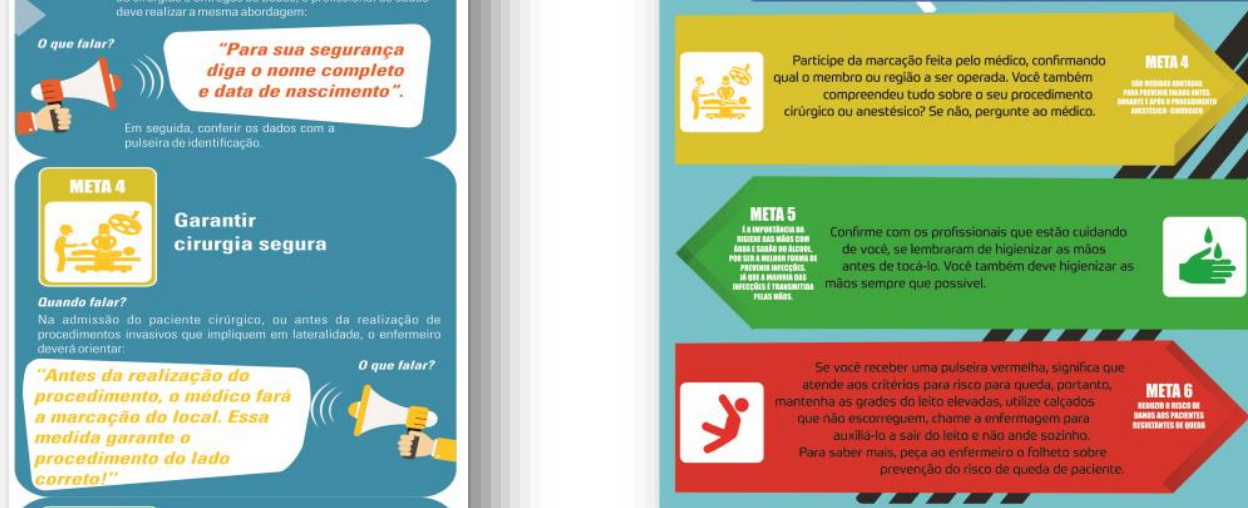

Garantir

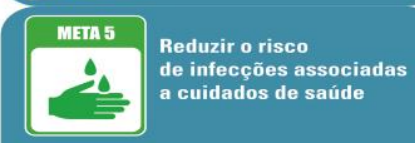

auando fatar?
Ao inciar o planta.
and

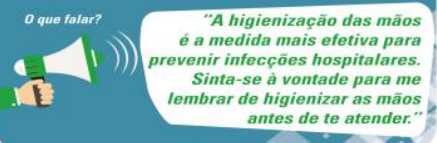

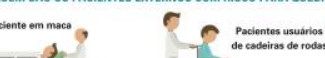

एक

(ब)-

in 1 III)

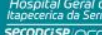

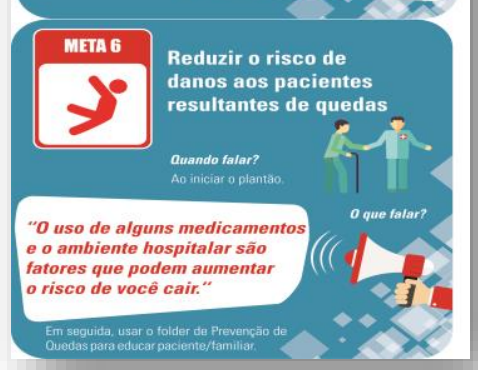

III

Prevenção de Quedas

Orientações aos usuários externos

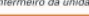

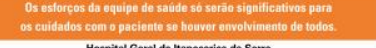




\begin{tabular}{|c|c|c|c|c|}
\hline META & INDICADOR & META & $\begin{array}{l}\text { PRIMEIRO } \\
\text { PERIOODO } \\
2012\end{array}$ & $\begin{array}{l}\text { ÚLTIMO } \\
\text { PERÍODO } \\
2018\end{array}$ \\
\hline 1 & $\begin{array}{c}\text { Taxa de adesão à } \\
\text { correta identificação } \\
\text { do paciente }\end{array}$ & $90 \%$ & $46,1 \%$ & $91,1 \%$ \\
\hline 2 & $\begin{array}{c}\text { Taxa de adesão ao POP } \\
\text { do ler de volta }\end{array}$ & $85 \%$ & $22,6 \%$ & $90,4 \%$ \\
\hline 3 & $\begin{array}{l}\text { Densidade de quase- } \\
\text { eventos na utilização } \\
\text { de medicamentos de } \\
\text { alta vigilância }\end{array}$ & $\begin{array}{c}\text { 0,05 quase- } \\
\text { eventos/ } 1000 \\
\text { pacientes-dia }\end{array}$ & $\begin{array}{c}0,6 \text { quase- } \\
\text { evento/10 } \\
00 \\
\text { paciente- } \\
\text { dia }\end{array}$ & $\begin{array}{c}0,05 \text { quase- } \\
\text { evento / } \\
1000 \\
\text { paciente-dia }\end{array}$ \\
\hline 4 & $\begin{array}{c}\text { Taxa de marcação de } \\
\text { sítio cirúrgico }\end{array}$ & $99 \%$ & $87,3 \%$ & $96,8 \%$ \\
\hline 5 & $\begin{array}{c}\text { Taxa de adesão à } \\
\text { higienização das mãos } \\
\text { nas UTI's }\end{array}$ & $70 \%$ & $47,4 \%$ & $89,0 \%$ \\
\hline 6 & $\begin{array}{c}\text { Incidência de queda de } \\
\text { paciente }\end{array}$ & $\begin{array}{l}\text { 0,6 quedas por } \\
1000 \text { pacientes- } \\
\text { dia } \\
\text { https://p }\end{array}$ & $\begin{array}{c}1,05 \\
\text { quedas } \\
\text { por } 1000 \\
\text { pacientes- } \\
\text { dila }\end{array}$ & $\begin{array}{c}0,78 \text { quedas } \\
\text { / } 1000 \\
\text { pacientes- } \\
\text { dia } \\
\text { 12224?lang=pt-br }\end{array}$ \\
\hline
\end{tabular}




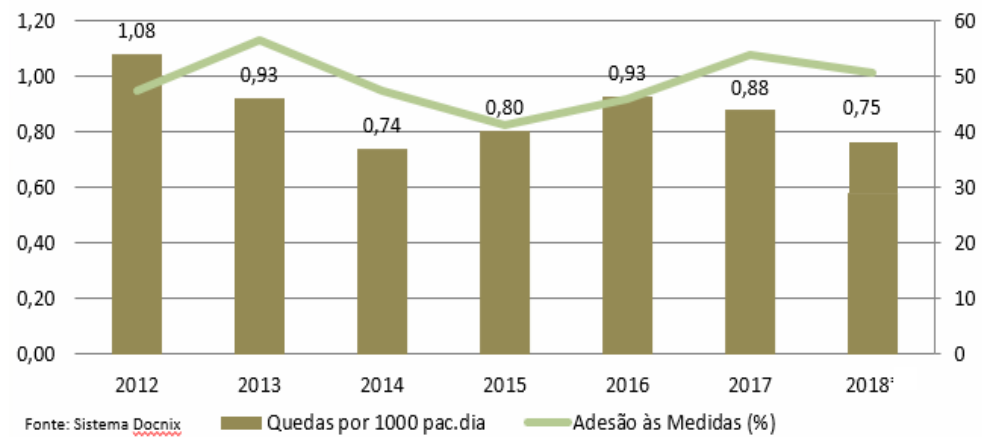

Série Histórica das Notificações de Incidentes 2008-2018

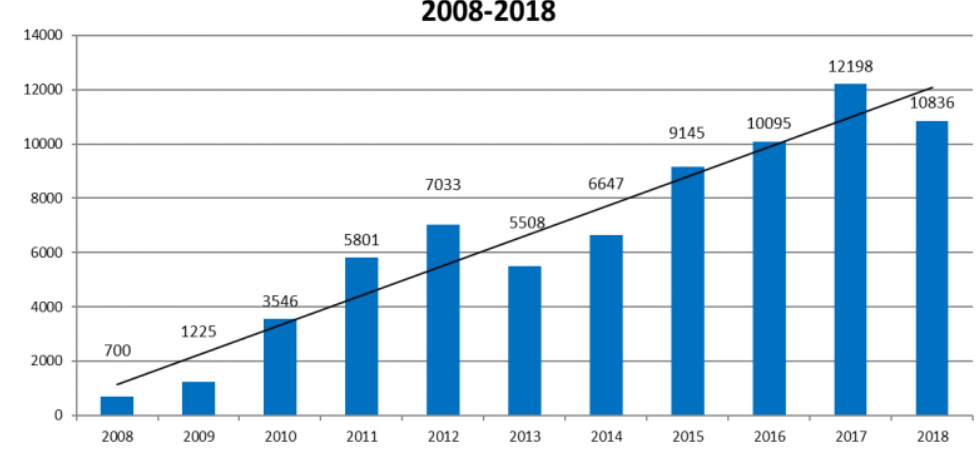

Fonte: Serviço de Vigilância de Risco

Taxa de eventos com dano (por 100 saídas hospitalares)

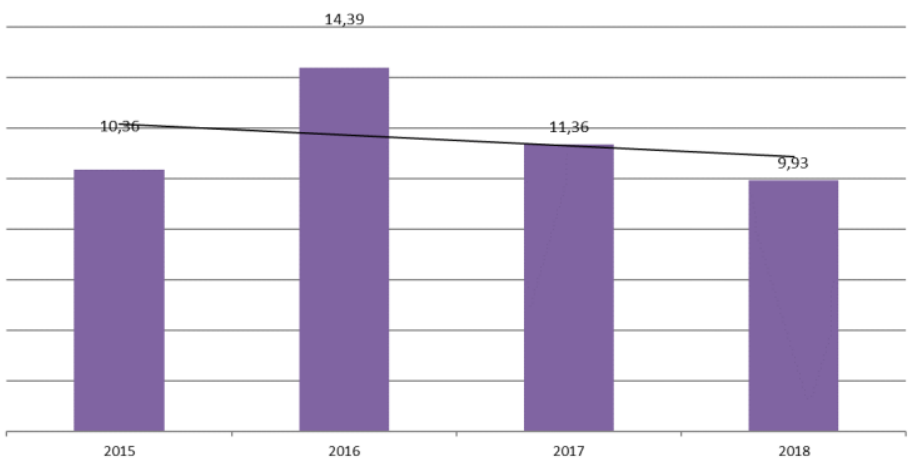


Conclusões

\section{mplantoçăo bem sucedidol}

Impacto na disseminação e fortalecimento da cultura de segurança com a melhora na adesão às políticas institucionais e redução de eventos adversos 


\section{Conclusões}

Expectativas e açōes de promoção de segurança da chefla

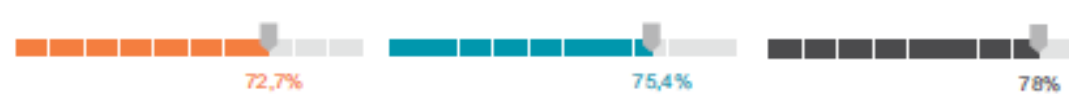

Aprendizado

organizacional e melhoria contínua

Apolo da gestão

hospitalar para a segurança do paciente

\section{Retorno das}

informações e da comunicaçăo sobre erro
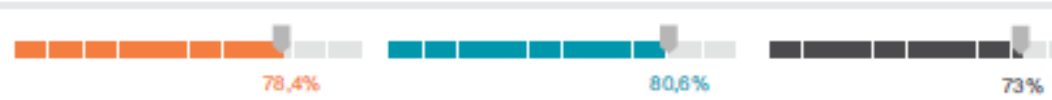

$73 \%$

Frequência de eventos notificados
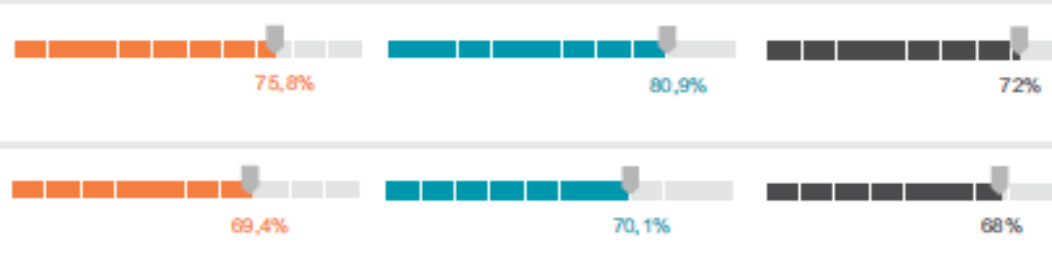

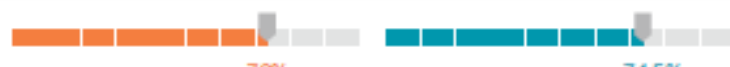
$72 \%$

$74,5 \%$

Percepçăo geral da segurança do paciente
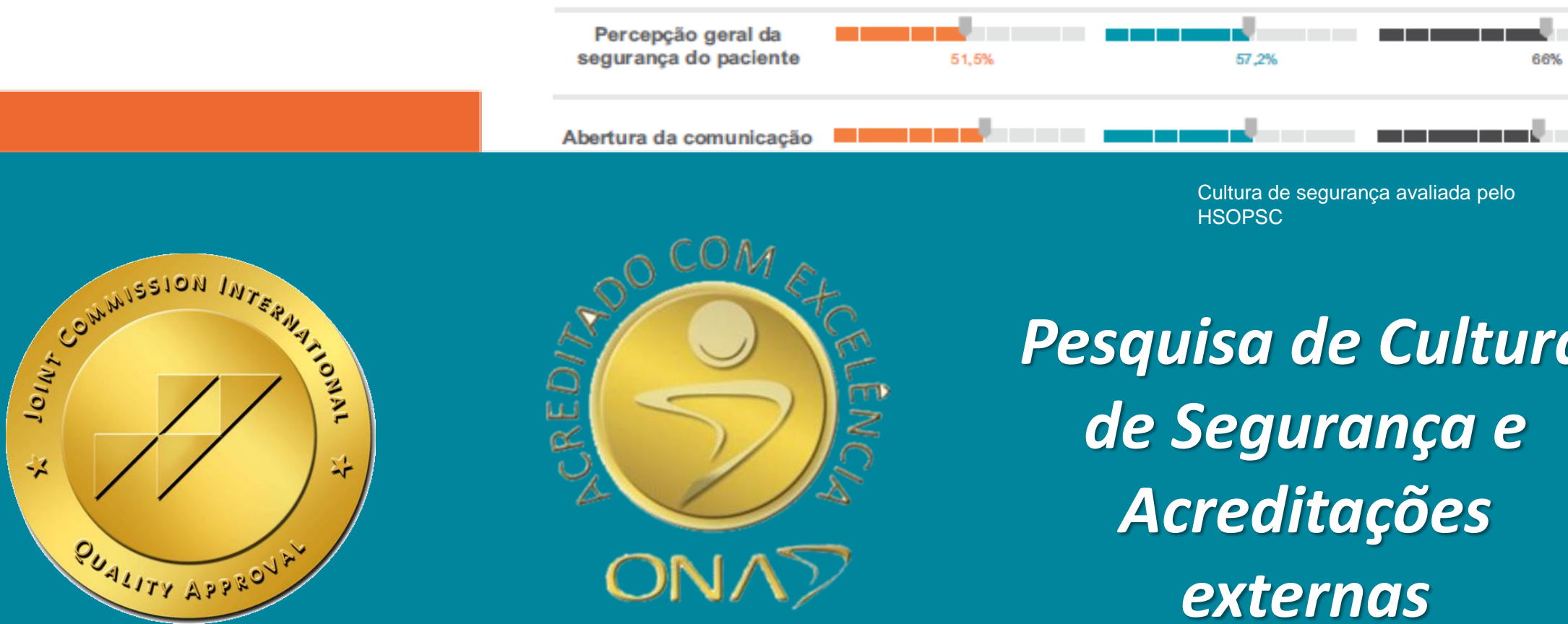

\section{Pesquisa de Cultura de Segurança e Acreditações externas}




\section{Conclusões}

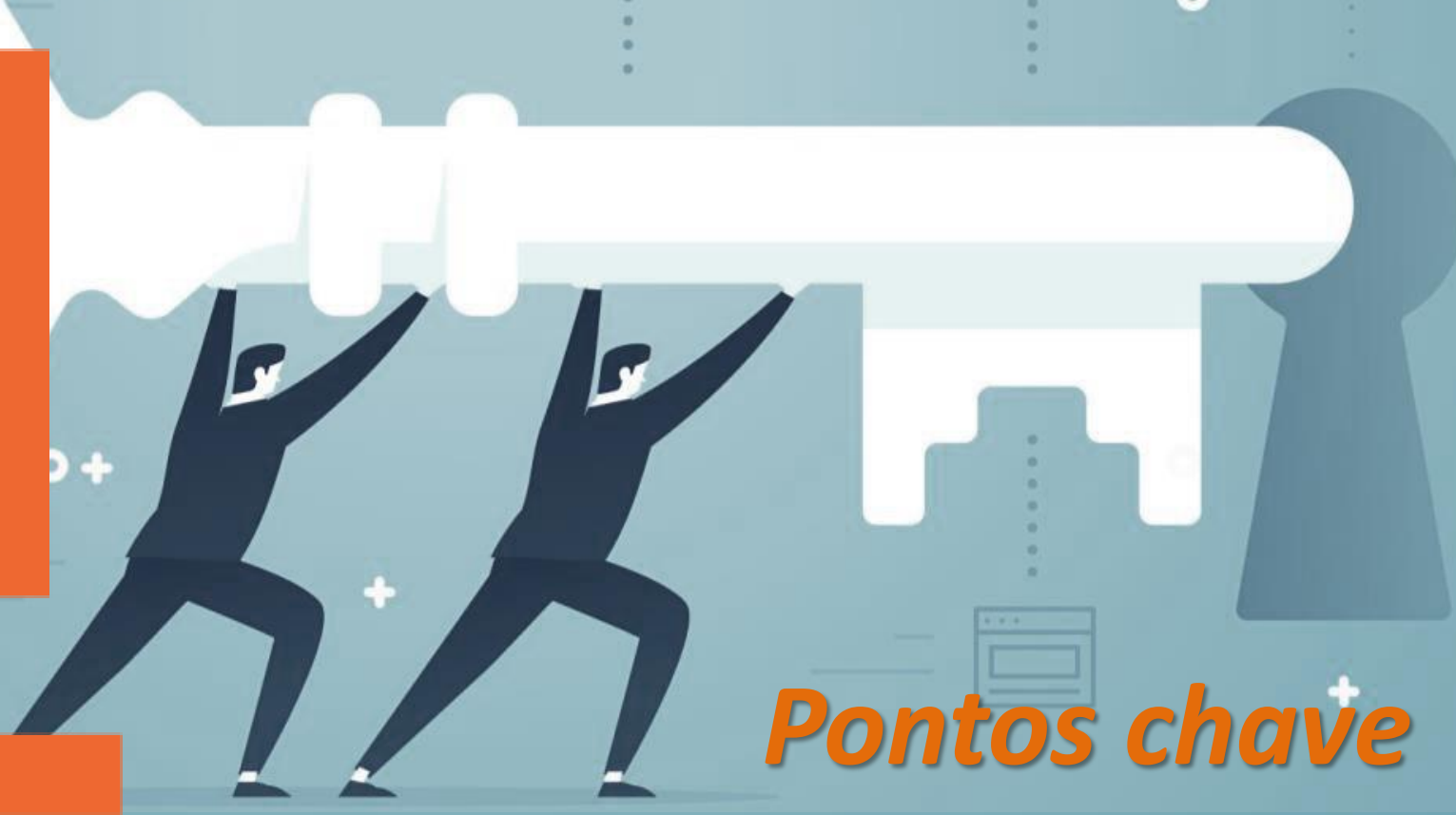

- Apoio e priorização da alta direção

- Envolvimento multiprofissional

- Estratégias variadas de divulgação e capacitação

- Monitoramento por meio de auditorias e indicadores para definição de estratégias e melhoria contínua dos processos 


\section{Obrigada}

Lisiane Valdez Gaspary

lisiane.gaspary@hgis.org.br 